\title{
A rare reason/cause of esophageal obstruction: Steakhouse syndrome
}

\author{
Öztekin Çıkman ${ }^{1, *}$, Şükrü Taş ${ }^{1}$, Hasan Ali Kiraz ${ }^{2}$, Ömer Faruk Özkan ${ }^{1}$, Gürhan Adam ${ }^{1}$, Muammer \\ Karaayvaz $^{3}$ \\ ${ }^{1}$ Department of General Surgery, Faculty of Medicine, Canakkale Onsekiz. Mart University, Canakeale, Turkey \\ ${ }^{2}$ Department of Anesthesiology and Reanimation, Faculty of Medicine, Canakkale Onsekiz. Mart University, \\ Canakeale, Turkey \\ ${ }^{3}$ Department of Radiology, Faculty of Medicine, Canakkale Onsekiz, Mart University, Canakkale, Turkey
}

\begin{abstract}
Steakhouse syndrome is an esophageal acute obstruction, due to improperly chewed meat. In most cases the etiology cannot be exactly shown, it is seen more frequently in patients with motility disorders in the lower esophageal sphincter and in alcoholics. Medical history and endoscopic examination are the first to be done for diagnosis. The endoscopic removal of foreign body after the diagnosis of obstruction is the most effective treatment method.
\end{abstract}

Key Words: Acute esophageal obstruction, Steakhouse syndrome, endoscopic examination

\section{Introduction}

Steakhouse syndrome, which has been described as acute esophageal obstruction due to inadequately chewed meat, was first reported by Norton in 1963 (1). However, before that, in 1945 Richardson et al. (2) has reported seventeen cases with meat impaction in the distal esophagus. It is a rare cause of dysphagia and also a medical emergency. It is usually associated with alcohol abuse, esophageal stenosis and disorders such as achalasia, nutcracker esophagus (3). Herein we present a patient with Steakhouse syndrome, admitted to our emergency department with acute dysphagia.

\section{Case report}

A 76 years old, female patient admitted to the emergency department for, nausea, dysphagia and retrosternal pain. Patient had no history of alcohol consumption or motility disorder. Venous cannulation with $20 \mathrm{G}$ angiocath was performed on the left hand of the patient in ASA II risk group after getting consent for anesthesia outside the operating room. Than $100 \mathrm{ml} / \mathrm{h}$ saline infusion was started. Ten minutes before the process, it was aimed to increase the $\mathrm{pH}$ of the gastric fluid with Ranitidine HCI $50 \mathrm{mg}$. Nasal oxygen supplementation $4 \mathrm{~L} / \mathrm{min}$ was started. Monitorization of DII lead ECG, $\mathrm{SpO}_{2}$ and noninvasive blood pressure was provided. For analgesia, $50 \mathrm{mcg}$ fentanyl citrate iv bolus was administered before 5 minutes of the process. Than $1 \mathrm{mg}$ midazolam iv bolus was given. Propofol iv bolus of $40 \mathrm{mg}$ was administered before 30 seconds of the process and moderate sedation was achieved. During the process, $15 \mathrm{mg}$ propofol was administered intermittaently at four times.

Upper gastrointestinal system endoscopy was performed which revealed a mass lesion at $35 \mathrm{~cm}$ from incisors. The mass completely filled the lumen, contained muscle fibers and blocked the passage disallowing the advancement of the scope. The lesion was determined to be a foreign body in the esophagus lumen (Figure 1). An endoscopic removal of the foreign body in the esophagus lumen was successfully performed, further examination and a more detailed history revealed it to be tough meat which was not chewed completely. The process lasted 20 minutes and patient was sent to the service after 30 minutes with modified Aldrete score 9 and no respiratory and hemodynamic problem was observed. The complaints of the patient decreased significantly.

\section{Discussion}

Steakhouse syndrome commonly presents with acute dysphagia symptoms and develops as a consequence of meat lodged in the esophagus, after being chewed

*Corresponding Author: Öztekin Ç1kman, MD, Assistant Professor, Çanakkale Onsekiz Mart University, Faculty of Medicine, Department of General Surgery, 17100, Kepez/Çanakkale, Turkey, Mobile Phone: +9 053346465 77, E-mail: droztekin67@hotmail.com Received: 29.01.2015, Accepted: 20.03.2015 


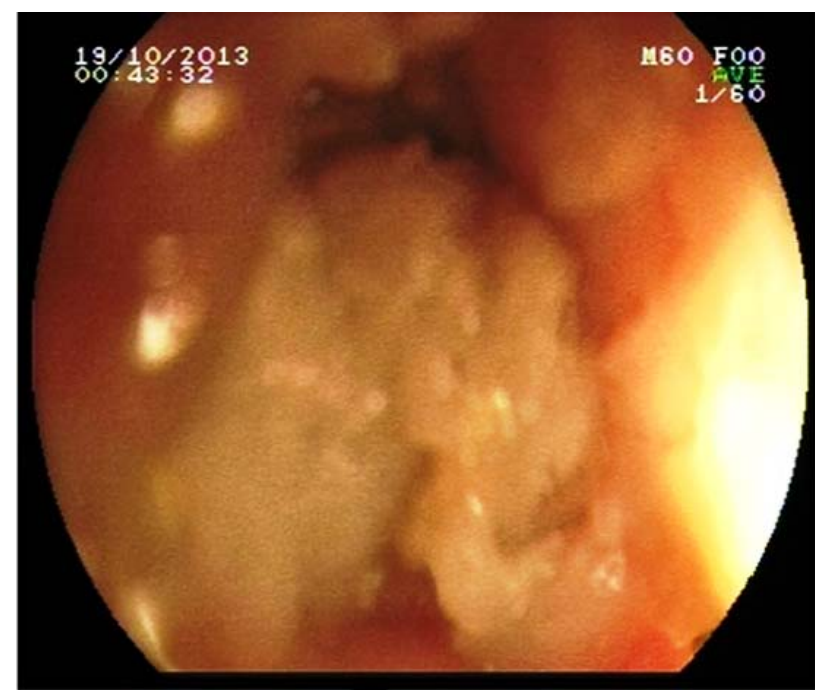

Fig. 1. Upper gastrointestinal system endoscopy revealed a mass lesion at $35 \mathrm{~cm}$ from incisors. The mass filled the lumen completely, contained muscle fibers and blocked the passage.

quickly and incompletely (1). It is seen more frequently in patients with motility disorders in the lower esophageal sphincter and in alcoholics Possible reasons for Steakhouse syndrome include. Esophageal webs, hiatal hernia, reflux esophagitis with stricture and malignant lesions $(1,3)$. It is important to identify the underlying cause. Various factors have been linked to Steakhouse syndrome such as esophageal stenosis and motility disorders, there may be no obvious cause. Previous studies have also demonstrated that alcohol consumption regardless of the dose and type, causes a reduction in esophageal motility (4). In this case, etiologic factors were excluded by using imaging techniques and patient's history. The causative factors were not identified in our patient.

In conclusion, careful medical history and endoscopic examination are the first to be done for diagnosis and treatment of food impaction of the esophagus (5). Although currently therapeutic endoscopy is the preferred procedure for treatment, historically nasoesophageal administration of enzymes have also been utilized (6).

\section{References}

1. Enomoto S, Nakazawa K, Ueda K, et al. Steakhouse syndrome causing large esophageal ulcer and stenosis. World J Gastrointest Endosc 2011; 3: 101-104.

2. Richardson JR. A new treatment for esophageal obstruction due to meat impaction. Ann Otol Rhinol Laryngol 1945; 54: 328-348.

3. Chae HS, Lee TK, Kim YW, et al. Two cases of steakhouse syndrome associated with nutcracker esophagus. Dis Esophagus 2002; 15: 330-333.

4. Bujanda L. The effects of alcohol consumption upon the gastrointestinal tract. Am J Gastroenterol 2000; 95: 3374-3382.

5. Webb WA. Management of foreign bodies of the upper gastrointestinal tract: update. Gastrointest Endosc 1995; 41: 39-51.

6. Nighbert E, Dorton H, Griffen WO Jr. Enzymatic relief of the "steakhouse syndrome". Am J Surg 1968; 116: 467-469. 